University of South Florida

DIGITAL COMMONS

Digital Commons @ University of

@ UNIVERSITY OF SOUTH FLORIDA

South Florida

Academic Services Faculty and Staff

Publications

Tampa Library

June 2011

\title{
Making Decisions: Using Electronic Data Collection to Re-Envision Reference Services at the USF Tampa Libraries
}

\author{
Lily Todorinova \\ University of South Florida, lily.todorinova@rutgers.edu \\ Barbara Lewis \\ University of South Florida, blewis@usf.edu \\ Andy Huse \\ University of South Florida, ahuse@usf.edu \\ Matt Torrence \\ University of South Florida, torrence@usf.edu
}

Follow this and additional works at: https://digitalcommons.usf.edu/tlas_pub

Part of the Library and Information Science Commons

\section{Scholar Commons Citation}

Todorinova, Lily; Lewis, Barbara; Huse, Andy; and Torrence, Matt, "Making Decisions: Using Electronic Data Collection to Re-Envision Reference Services at the USF Tampa Libraries" (2011). Academic Services Faculty and Staff Publications. 50.

https://digitalcommons.usf.edu/tlas_pub/50

This Article is brought to you for free and open access by the Tampa Library at Digital Commons @ University of South Florida. It has been accepted for inclusion in Academic Services Faculty and Staff Publications by an authorized administrator of Digital Commons @ University of South Florida. For more information, please contact digitalcommons@usf.edu. 
Making Decisions: Using Electronic Data Collection to Re-Envision Reference Services at the USF Tampa Libraries

Lily Todorinova University of South Florida-Tampa Libraries, Academic Services. Email: 1todorinova@usf.edu

Andy Huse University of South Florida-Tampa Libraries, Special \& Digital Collections. Email: ahuse@usf.edu

Barbara Lewis University of South Florida-Tampa Libraries, Special \& Digital Collections. Email: bilewis@usf.edu

Matt Torrence University of South Florida-Tampa Libraries, Academic Services.

Email: torrence@usf.edu 


\begin{abstract}
Declining reference statistics, diminishing human resources, and the desire to be more proactive and embedded in academic departments, prompted the University of South Florida Library to create a taskforce for re-envisioning reference services. The taskforce was charged with examining the staffing patterns at the desk and developing recommendations to give librarians greater flexibility and to better respond to the information-seeking needs of users. These recommendations were based on statistics of desk usage, collected with the newly adapted online tool Desk Tracker, and structured interviews with library administrators. The taskforce was interested in how these stakeholders use quantitative data in decision-making. Headings: Academic Libraries, Special Collections, Reference Services, Staffing, Assessment, Desk Tracker, Administration, Virtual Reference, Tiered Reference
\end{abstract}




\section{Introduction}

In the Fall of 2010, prompted by declining reference statistics, diminishing human resources, as well as a charge to be more proactive and embedded in the University of South Florida Tampa (USF) academic departments, the library organized a taskforce to re-envision reference services. The taskforce critically examined the staffing patterns and usage of the reference desk using Desk Tracker-a web-based tool for recording transactions. The essential problem addressed was: Is the reference desk staffed in a way that accommodates the needs of $21^{\text {st }}$ century learners? The project concluded by recommending to library administrators a new desk model for Spring of 2011, including expanding the role of paraprofessionals and students, instituting an on-call tiered referral system, as well as focusing on creating a culture of continuous assessment, innovation, and experimentation for public services.

This paper will examine the methods used by the taskforce to arrive at these recommendations, many of which have since been adopted in Special \& Digital Collections and the general reference desk. The taskforce was successful in influencing institutional change through the use of quantitative data, as well as structured interviews, which deliberately explored the processes used by library administrators to mandate changes. This paper will examine the history of reference services at USF Tampa, the context for the re-envisioning project, the impact of the adoption of the electronic data collection tool, the recommendations the project members produced, as well as how structured interviews informed decisions made by library administrators in implementing these recommendations. The professional literature regarding decision-making in academic libraries and the impact of virtual reference on public services staffing will also be reviewed. Finally, the authors will 
share the preliminary results of this project, which include instituting an on-call model of reference in Special \& Digital Collections and a modified tiered model for the general desk, including library faculty office hours, increased virtual reference, and limited night and weekend hours. It is hoped that this experience will inform other professionals of one institution's successful re-envisioning of the traditional "desk bound" reference model, while also addressing a scarcity in the literature on how library administrators reach decisions using quantitative data.

\section{Background}

The University of South Florida is a large urban research university with an enrollment of approximately 47,000 students, 40,000 of which are based at the Tampa Campus. The Tampa Library is the institute's main library, which houses both Academic Services and Special \& Digital Collections, as well as partner services, such as Tutoring and Learning Services, the Writing Center, and Information Technology. The Louis de la Parte Florida Mental Health Institute Research Library (FMHI) is a special library located across campus. These units, along with the USF Sarasota-Manatee and USF Polytechnic affiliated regional libraries, constitute the USF Libraries system.

\section{Context for the Project}

The evolving nature of academic libraries, the changing needs of their patrons, and a desire for greater integration of library departments, required a reassessment of how USF Libraries deliver reference services throughout the entire system, as well as recommendations on how these services can be sustained and improved. In its ideal, a reference service should demonstrate high patron satisfaction and align human resources in accordance with these expectations, as well as the goals and budgetary realities of the institution. 
A task force, representing librarians in Academic Services, Special \& Digital Collections, and the FMHI Library, was formed to review professional literature and standards on delivering and assessing reference services, collect and analyze relevant data, as well as make recommendations on best practices, delivery models, assessment, and continuous improvement strategies. Before these changes were implemented, the reference model at USF Tampa library was very traditional, both spatially and in terms of staffing patterns. The taskforce perceived that the reality of reference at primary service points was not in concert with the innovative models that have emerged from the Learning Commons concept. In the past, the library had experimented with combining service points with Information Technology (IT), but the experiment was ultimately ineffective in the context of the particular institution. Unlike peer and aspirant libraries, USF Tampa does not have a strong digital media and productions focus and, therefore, very little need for advanced technological reference. Everyday reference interactions are primarily about information retrieval, not information production, which contributed to the inability of the reference and IT desks to truly integrate services, as opposed to simply combine them.

\section{The Reference Desk: Prior to Re-Envisioning}

In the Fall of 2010, the desk was moved again, this time positioning it closer to the Writing Center and Circulation desk. This model is an emerging feature of Learning Commons, although, so far, due to unstructured and largely inconsistent referral processes, the improvement opportunities created by the physical proximity of these units have not been fully explored. Nevertheless, by collocating these services there is an increased awareness of collegial services and activities. This allows for greater efficiency in helping patrons to find the right services, as well as to transition between them. Another benefit of this model is its 
parallel in teaching and researching, namely, the university's clustering of academic departments in the Arts and Sciences. By combining service points and by continuous interdepartmental collaboration, the library is in concert with the mission and goals of the university as a whole, in promoting partnerships that foster student learning.

At the start of this assessment, the total faculty librarian time used at the general reference desk was approximately 110 hours per week. Reference librarians interacted with patrons in a number of ways, including face-to-face, telephone, and chat. In addition, reference services were provided off-desk through scheduled consulting services offered by subject specialists in their offices. Graduate Assistants (GAs) staffed the desk with a librarian during most of the hours the desk was open $(9 \mathrm{am}-11 \mathrm{pm})$, but the desk was never staffed by paraprofessionals and students alone. One, or often two, professional librarians were nearly always present on the reference desk. This eventually contributed to dissatisfaction from the staff in "being stretched too thin" and not having enough time for other activities, such as being embedded in academic departments. The Re-Envisioning Taskforce was prompted to examine the relationship between reference, as a concept, and the physical desk, and the costeffectiveness of staffing the desk with library faculty, as opposed to paraprofessionals and students (Ryan, 2008).

\section{Preliminary Analysis: Reference Interaction Statistics}

At the start of the project, the taskforce collected and analyzed data provided by Compendium Library Services’ Desk Tracker - a transaction collection and reporting tool, which was recently implemented. Data-gathering instruments are not a new development, but many libraries are still learning the value and effectiveness of recording statistics electronically. Generally, these tools are easy to manage from a technical standpoint and 
allow for separating transactions into categories, the ability to enter data in multiple ways, as well as the creation of customized reports. The categories used at the USF Tampa general reference desk include: Directional, Basic, Advanced, Technical, or Other. One of the most valuable features of online data collection instruments is that they allow for categories to be developed and expanded over time, which was certainly beneficial, as the taskforce became more aware of its data-collecting needs. The use of electronic data collection, ultimately, allowed the taskforce to strategically plan how, when, and where to collect the transaction data that will have the most impact on decision-making.

The data collected with this mechanism showed a trend that was anticipated by a review of the literature on reference statistics, namely: a significant decline in advanced reference interactions, as well as predictable times of peak and low reference activity. This prompted the taskforce to suspect that the staffing patterns at the reference desk were inconsistent with the behaviors and needs of library users. It also begged an important question, asked by other library professionals, according to the literature: If students and faculty did not use the reference desk for advanced research inquiries, where were these inquiries going and how can librarians be more actively embedded in the information-seeking behaviors of $21^{\text {st }}$ century learners (Bracke, Brewer, \& Huff-Eibl, 2007)?

\section{Recommendations}

After looking at the actual patterns of usage for the reference desk and the literature on reference assessment at peer institutions, the Re-Envisioning Taskforce arrived at some preliminary recommendations:

- Single staffing librarians and graduate assistants at peak reference times only

- Instituting a robust referral system between graduate assistants and librarians, as well as 
among departments and collaborators (such as the Writing Center and Tutoring \& Learning)

- Assigning librarian office hours when the desk is single-staffed by graduate assistants or paraprofessionals

- Eliminating night hours and reassessing weekend staffing

- Increasing virtual reference

- Creating a strong paraprofessional and graduate assistant training program Many of these recommendations have since been adopted by the Academic Services and Special \& Digital Collections departments, while the FMHI Research Library had, prior to the re-envisioning project, successfully instituted a tiered, on-call model. Because virtual reference is essential to eliminating staff time on the actual desk, it will be discussed in additional detail in the following section.

\section{Virtual Reference}

When thinking about how to effectively serve the academic library patron population, it is clear that virtual reference tools represent a huge part of the next model of service. The Internet has allowed for the expansion of electronic reference via chat, text, email, and the use of other new tools and technologies. Services once thought to be cutting-edge, or necessary only for distance learners, are now everyday research options for patrons and librarians. It is frequently mentioned in the literature that reference services have traditionally been very efficient in providing access to the print and other collections contained within the library edifice (Joint, 2008 p. 418). The advent of electronic information, however, changed this equation, by introducing new modes of contact and communication. As we explore a redesign of reference services, it is essential to include these virtual reference activities as a 
continuing partner to traditional librarian availability.

Staffing and visibility are two primary issues that bring more weight to the creative and effective use of virtual reference services. There are numerous cooperative advantages to electronic reference, including the automatic creation of a transcribed record of each reference transaction (Nilsen, 2006, p. 98). This allows for easy collaboration with other library colleagues, as well as ease of forwarding if an inquiry needs to be directed to a subject, or other specialist. In researching the comparison of users' perspectives of in-person and virtual services, one author stresses the importance of following-up with research clients. This task is much easier when a written record is readily available and electronic notification is set to provide contact reminders (Nilsen, 2006, p. 101). The sustained development of these services at USF, as well as investigation into emerging technologies, will benefit all of those that provide public service. This will increase the ability of library personnel to manage points of contact and revisit patron needs in a timely fashion.

Digital reference services are loaded with attractive qualities, but there are some important primary issues that must be addressed. While virtual and electronic methods of communication provide additional points of access and ease of patron and librarian contact, there are serious service satisfaction concerns that must be addressed. A recent academic library study determined that patrons inside the library continue to prefer a reference librarian to virtual forms of reference (Cummings, Cummings, and Frederiksen, 2007, p. 89). When the same question was posed to those working outside the library walls, the library website arose as the clear top choice, with chat the least popular option (Cummings, Cummings, and Frederiksen, 2007). With these warnings to heed, chat, email, and other forms of reference must endure constant assessment and refinement to maximize the chance of success. 
Virtual reference contact points and services are clearly important current and future options for providing library and research assistance. Combining these electronic modes of contact with traditional in-person availability will be a constant challenge, but by continuously assessing patron use and preferences, data may be effectively collected for future decision-making. In the short term, one possibility was to shift more night and weekend reference services to electronic and collaborative functions. USF Libraries' participation with the Tampa Bay Library Consortium's Ask-A-Librarian cooperative has been successful to date and could be relied upon for additional coverage in the future.

Chat and texting services are conducive to collaborative efforts with partner libraries, especially with the development of good scheduling and knowledge-based resources for each collaborating institution. It is conceivable that not all questions may be effectively answered using these forms of communication, but, at the very least, they do allow for easy triage and referral. Once the statistics have been gathered, librarians can target the times most heavily used by patrons and staff those hours with local agents. The chat collaborative may then be comfortably relied upon for timely response and referral during lesser-used periods. While in-person interactions are appreciated and preferred by those inside the library, research indicates that patrons expect and favor chat and email services for "times outside the standard business hours" (Cummings, Cummings, and Frederiksen, 2007, p. 92). These findings support our movement to service enhancement through collaborative chat, while concurrently encouraging better utilization of staff time and efforts for email and other forms of digital reference.

Scheduling librarians to be on-call, while relying on graduate assistants and paraprofessionals for night and weekends, was also among the recommendations of the re- 
envisioning taskforce, which was adopted at the general reference desk. This allows for someone to monitor services within the building remotely, while also responding to email inquiries received during the slow service times. Virtual reference also allows librarians the flexibility of providing the service from their offices or homes, while also engaging in other activities, such as collection development, instructional support and planning, and research.

\section{Decision-making in Academic Libraries}

The role of the Re-envisioning Taskforce was not only to collect and analyze data, both within and outside of the institution, and to create recommendations for staffing the reference desk, but also to ensure that these recommendations are realistic and implementable in the next semester. In order to do so, the taskforce perceived the importance of approaching the problem from the point of view of the library administrators who will ultimately approve the implementation of these changes. The taskforce wanted to understand how these administrators actually reach decisions and how they have used quantitative data in the past to implement changes.

The literature is sparse of reports on the actual decision-making processes of library administrators. Furthermore, it shows that structured stakeholder interviews have virtually not been used to gain insight into decision-making. Using quantitative data to affect institutional change is sometimes referred to in the literature as "evidence-based librarianship" (Bayley, 2009, p. 236). In its essence, it is the practice of applying empirical support to the daily practices of the profession. In a field that has often struggled to assert itself in quantitative methods, this is not currently a common approach to decision-making. Administrative and staffing decisions especially are very complex and arriving at them is not always a purely rational task. 
A project team with a charge very similar to the one of the Re-envisioning Reference Taskforce at USF was formed in 2007 at the University of Arizona Libraries (UAL). This group arrived at recommendations by analyzing reference questions, surveying the customer perspective, and analyzing the actual cost of reference services (Bracke, Brewer, \& HuffEibl, 2007, p. 261). The last method appeals especially to library administrators and provides rationale for implementing change. The UAL team stressed the importance of consistent quantitative data collection and how it can affect practical change by "[making] it difficult for the few remaining reference traditionalists to claim that their absence from the desk would result in a catastrophic decline in the quality of service" (p. 261). Their approach was ultimately successful in convincing library staff to move to a tired reference desk model, staffed by paraprofessionals and students.

The key to the success of UAL was that it did not underestimate the difficulty of change. They were ultimately very successful in presenting quantitative data and using it to evoke institutional change, which affirms the validity of evidence-based practice. The Reenvisioning Reference Taskforce at USF Tampa, however, was interested in investigating a bit further just how quantitative data is actually used by library administration. Hines (2009) uses the "bounded rationality" model to describe how users often find information, which is not always a straight line. In contrast to evidence-based practice, bounded rationality is the idea that "people may make decisions without all the information they could gather" (p. 81). It affects how users navigate resources and reach day-to-day decisions, but, similarly, it can also be applied to the ways in which library directors and administrators deal with day-to-day operations. Hines (2009) suggests that librarians are too quantitatively rational, and often overlook the heuristics users may apply in practice (p. 83). When it comes to administrative 
decisions, Schachter (2006) and others have suggested that librarians often approach decision-making in a similar unstructured way.

The "bounded rationality" model, applicable to both librarians and end-users, implies a limit to the ability of professionals to use only quantitative and rational data to arrive at decisions, for which there are innumerable behavioral and human implications and considerations. Because library science is an inherently practice-based discipline, we must always remember that we deal not only with decisions, but their consequences (Hines, 2009, p. 81). It is as much about consensus building as it is about decision-making (Schachter, 2006, p. 12).

In light of this, the members of the taskforce attempted to remain realistic regarding staffing recommendations. It was understood that in order to affect immediate change to current patterns, it was imperative to objectively consider the manner in which library administration will make and implement any final decisions. In our survey of the relevant literature on staffing decisions, we found that there was virtually nothing written on using structured interviews with key stakeholders and administrators to examine their rationales for implementing decisions.

\section{Data Collection, Decision-Making and Semi-Structured Interviews}

In November 2010, interviews were conducted with administrators and librarians to collect information on the relationship between data and decision-making, across units within the USF Tampa Library and the FMHI Research Library, with a particular emphasis on the provision of reference services. Each interview, which was recorded and transcribed, consisted of a series of open-ended questions with the intent to elicit and understand the types of data collected in the past and how this data was used in operational decision-making. 
The first set of questions pertained to the type of data collected during the past five years, types of instruments used to collect the data, and how the respondents used it in deciding changes in the operations of reference services in their unit.

At the reference desk, various methods had been used to record the number and types of questions, prior to adopting an electronic data collection tool. Initially, mechanical clickers were used to record the count of simple, advanced, and technical questions asked during a one-week period each month. These numbers were multiplied by four to estimate the number of questions asked during the month. This method was deemed weak because the time of day that the question was asked was not recorded and there was concern that the tallies were inaccurate. The mechanical clickers were replaced by tally sheets, which recorded the same information but included the hour in which the questions were asked. Although this was an improvement over the use of the mechanical clickers, there were still concerns about underreported or exaggerated numbers and the use of sampling for one-week per month to develop monthly estimates.

Although the data from these collection methods was not wholly trusted, it nevertheless had an impact on organizational decisions, such as the hours that the reference desk was open, the number of staff members at the desk each hour, and the number of desk hours assigned to each staff member. Using another benefit of the new online transaction-recording tool, namely, the ability to record comments, additional data was collected and used to determine how late the reference desk should be staffed. For a two-week period one semester, the graduate assistants staffing the desk between $8 \mathrm{pm}$ and closing at $11 \mathrm{pm}$ were asked to record the actual questions asked and the time. This method was used to recommend that the desk should not be staffed after 9 pm. 
Special \& Digital Collections at the USF Tampa Library also used several methods to collect data on reference transactions. Logs of email questions have been kept and reported, mechanical clickers have been used to count the number of questions asked at the Reading Room Desk, and call slips and circulation statistics have been tabulated to determine what collections are being used and to infer information about the interaction with the patron. Anecdotal "data," based on desk staff input about what patrons were asking has also been used in the process of making decisions about desk hours and staffing. However, as with the reference desk data, the data collection processes in Special \& Digital Collections were not considered systematic or methodologically sound. For example, customer interaction that occurs when a patron requests material, thereby triggering a call slip or check out, should not automatically be counted as a reference transaction. The clicker counts were also considered unreliable. Decision-making about reference issues in Special \& Digital Collections, such as staff training and required skill sets and desk scheduling, has primarily been experimental based on anecdotal input or based on internal issues like the loss of key personnel.

Reference service at the FMHI Research Library is unique in that there is not a physical reference desk at this library location. These services are carried out entirely in librarian offices, via email, and over the phone. Questions are identified as reference (under 30 minutes) or research (over 30 minutes). Tracking of directional data was discontinued due to staffing issues, the low volume of those types of questions, and its' considered lack of importance in the FMHI Research Library environment. In the past, each librarian used their own method to keep track of and report counts of the types of questions asked by each type of user (faculty, staff, student and level of student, community member, and affiliated faculty). As complete data is recorded for each question asked, the information is considered 
accurate and useful. However, since there is not a literal reference desk, the statistics are used primarily for collection development and not for desk staffing and scheduling.

Prior to the re-envisioning project, neither Reference nor Special \& Digital Collections had conducted systematic qualitative data collection, although some customer feedback was provided via unsolicited, usually positive, emails to librarians and administrators. There was also anecdotal data from frequent participation with and issuance of the LibQUAL survey. The FMHI Research Library has been more consistent in that respect. The special library receives customer feedback in a similar fashion to the main library, but supplements it by conducting annual attitudinal and perception surveys using yes/no, Likert scale, and openended questions. Each year, a department or unit of FMHI is surveyed about the library and its services. In addition, every two years they conduct a large survey regarding peoples' opinions and attitudes about reference services, usually with high response rates. Questions include how often they use the library's services, which services are most important, and what else the library should be doing.

These surveys are also used to evaluate new services and to rank existing services. The FMHI Research Library conducts expectation analyses to improve services, which compared librarians' perceptions of patron expectations with actual patron expectations. The perceived strength of these surveys is the feedback on patrons' general impression of the library and its' usefulness as a barometer of patron attitudes and identification of potential problem areas. The identified weaknesses are that they are unable to resurvey on a data sample as often as desired and that it is opinion data. The structured interviews with FMHI administrators were tremendously helpful to the general Tampa reference desk and Special \& Digital Collections in suggesting new and more structured ways of collecting information, which may not have 
been discovered otherwise.

The next section of questions asked the respondents to compare previous data collection efforts and decision-making with the ones the Re-Envisioning Taskforce arrived at, using of the electronic data collection tool. Overall, the administrators had a positive reaction to the new method of recording transactions. The data collected includes the type of patron (faculty, student, community member, etc.), the transaction forum (email, phone, faceto-face, etc.), and the type of question (directional, basic reference, advanced reference, etc.). Advantages include increased staff commitment to enter accurate data, the collection of all reference transaction and not just a sampling, the system's ease of use, the level of detail and configurability of the data that can be collected, the ability to export data, and traceability by staff member.

Despite the good reviews of the online data collection tool, a few weaknesses, such as limited report output options, minor navigation issues, manual analysis of comments, and time-out issues, have been identified. Interviewees also indicated that the use of Desk Tracker data would improve the decision-making process because the data was more complete and easier to access. An obvious type of decision that can be made based on this data is the appropriate staffing at service points. However, the potential usefulness of the data isn't restricted to staffing decisions. An analysis of the types of questions asked (e.g., about library policy or specific subject areas) could inform training requirements for desk staff and identify patron interest areas that affect collection development needs (Finnell \& Fontane, 2010, p. 281-2).

The questions in the final section of the interview asked the respondents to reflect on the role of decision-making and data in improving services and operations. There were a 
wide variety of areas that the interviewees would like to make data-driven decisions. Regarding reference services, the respondents indicated that, in addition to basic desk staffing/hours decisions, they want to identify skill sets required to staff various service points and to address training needs. They also want to be able to identify services that are no longer needed so that staff can be applied to more active service areas. Instruction needs, enhancement of collection development efforts, and outreach and collaborative opportunities were also identified as areas that could benefit from an analysis of reference transactions.

The data needed to accomplish this decision-making included who are our patrons, why patrons visit the library and use various services, when are patrons coming to the library and using services, who is serving them, what materials are patrons using, level of happiness/satisfaction with the transaction and impact of the interaction, and use expectations. One caveat expressed by two of the interviewees was that numbers alone should not drive an organization's decisions. The data should provide guidance and help inform decision-making, but cannot be the only source for information.

Finally, the respondents were asked about organizational factors that are significant in implementing organizational change. Concern was expressed that mandates would be made that do not reflect what the data indicates should be done or that changes would be impeded by the "that's the way we've always done it" attitude. In addition, the budget, staffing, and skill sets to do extensive assessment are necessary. As one interviewee expressed, a commitment to build a culture of assessment is needed, where numbers are not threatening and where data collection is second nature and recognized as valuable.

\section{Preliminary Results: Informed Decisions in Special Collections}

The first level of implementation of the recommendations generated by the Re- 
Envisioning Reference Taskforce targeted Special \& Digital Collections at the USF Tampa Library. As a smaller unit, Special and Digital Collections was able to absorb the lessons of the statistics immediately. For almost a decade, Special \& Digital Collections had been changing its desk policies and staffing and operating hours. The advent of the online datacollection tool provided the department with reliable statistics that had not previously been available. These statistics were used to reshape the way the desk is staffed.

In 2006, Special \& Digital Collections implemented a primary/backup system that usually called for Student Assistants (SAs) and GAs to work primary duty, while faculty and staff served a backup role, helping on-demand for more specialized reference inquiries. The problem with this approach was a schedule that was even more demanding than the old model - two people had to be scheduled on the desk at a given time. It was also open to misinterpretation, where primary and backups would work the desk together, instead of the backup going about their duties while being on-call. This model also put more constraints on faculty and staff schedules without any discernible benefit to patrons. Finally, such a model did not ensure that patrons would get the specialized help they needed. If the patron needed in-depth help with a children's book, for example, the history specialist would be of little use as backup.

Due to these issues, Special \& Digital Collections reverted to the single-person desk model in 2009, without any set backup hours. Under this model, library faculty would make themselves available for specialized reference services as they were needed. The department also cut evening hours (Wednesday and Thursday, from 6:00-8:00pm) for lack of patrons. Personnel cuts in 2010 prompted a shortening of desk hours (from 9-6 to 10-5 on weekdays).

This shortening of hours was accompanied by a "just in time" attitude to specialized 
reference, rather than "just in case," meaning that faculty would be available as long as they were in the office, but otherwise patrons would be encouraged to make an appointment for a research consultation.

In the summer of 2010, Special \& Digital Collections began to use Aeon, a commercial product, to circulate items, record Reading Room attendance, and keep statistics. In the fall, all faculty and staff began using Desk Tracker to record patron interaction in their offices and at the Reading Room desk. While these new systems solved many problems with organization and statistics, Aeon does present a slightly higher learning curve for newcomers, especially those with smaller time commitments on the desk, to gain proficiency in the new system.

Desk Tracker was implemented for keeping statistics in August, 2010. By October, sufficient numbers had been gathered to identify patterns of patron use. The statistics made it clear that the 9:1 ratio of basic to advanced reference questions held true at the Reading Room desk. Roughly one out of seven patrons required directional assistance unrelated to Special \& Digital Collection resources (i.e., "Where are the restrooms?", "Where is the juvenile collection?", etc.). The majority of patrons arrived knowing what materials they wanted to use and without the need for a reference interview. In Desk Tracker, Special \& Digital Collections staff members note this type of service as "retrieval."

These retrievals make up the bulk of the non-reference questions. The online data collection software permits a great deal of customization, allowing institutions to adapt the types and frequencies of statistics they keep. As of this writing, Special \& Digital Collections is adding a new category of patron interaction: the referral. When patrons are referred to other library or university faculty members for in-depth research consultations, desk staff 
typically recorded this in the notes field. Henceforth, referrals will be more closely observed in the system.

It became clear that patron use was low in the mornings and peaked during the early afternoon. To respond to this information, the Special \& Digital Collections director and faculty created and implemented a new desk schedule that relies on four people, two staff members and two GAs, to provide service at the desk during all scheduled hours. This relatively stable lineup has produced several positive outcomes: faculty are free to serve as desk backups, the creation of desk specialists with more experience, minimization of turnover and training, and easing of schedule creation. Best of all, the increase in desk hours for the four working the desk has been minimal, with no one person working more than 9-10 hours per week. The shortened desk hours have made it possible to consistently offer service at the public service desk with only a few people, without interfering with their regular duties.

This new method of staffing the desk moves Special \& Digital Collections in line with a Brandeis-type model, relying on paraprofessionals and students to handle retrievals and to refer patrons with more involved questions to the appropriate faculty for research consultations. The new system of online data collection has worked well and there is a confidence that future models will continue to be appropriate for our patrons' needs. Success in Special \& Digital Collections is encouraging, as Reference prepares to implement a new desk schedule based upon its own usage statistics.

\section{Conclusions}

USF Tampa Library is continuing to implement the recommendations from the ReEnvisioning project. As has been shown, a number of data-driven changes are already in 
place in the Special \& Digital Collections unit and FMHI. As a larger department with more traffic and differing usage patterns, the general reference desk is assimilating at its own pace, making the adjustments that are appropriate for the nature of its needs and users. Among the recommendations that have been adopted the Tampa reference desk has instituted an on-call system, where library faculty hold office hours at times when reference usage has been shown to be low. The total hours during which librarians are expected to be physically present at the desk have been reduced by half, while GAs and paraprofessionals are becoming the primary service providers. Virtual reference is also becoming a more essential component of library operations and, currently, reference is only available through chat on Saturdays.

The importance of the Re-Envisioning Reference project to USF Tampa Library is yet to be assessed; however, the prompt manner in which the taskforce's recommendations have already been adopted, suggests that this model of inter-departmental library collaboration and the use of both quantitative data and structured interviews of stakeholders is an effective means of influencing institutional change. Electronic data collection makes staffing experimentation more stable and allows for increased time and accuracy in the development of innovative strategies for integrated and efficient reference services. 


\section{References}

Bayley, L. (2009). Practicing what we preach: A case study on the application of evidencebased practice to inform decision making for public services staffing in an academic health sciences library. The New Review of Academic Librarianship, 15(2), 235-252. doi: $10.1080 / 13614530903245311$

Bracke, M. S., Brewer, M., \& Huff-Eibl, R. (2007). Finding information in a new landscape: Developing new service and staffing models for mediated information services. College \& Research Libraries, 68 (3), 248-267. Retrieved from http://crl.acrl.org/content/68/3/248.full.pdf+html

Cummings, J., Cummings, L., \& Frederiksen, L. (2007). User preferences in reference services: Virtual reference and academic libraries. Portal: Libraries and the Academy, 7(1), 81-96. doi: 10.1353/pla.2007.0004

Finnell, J., \& Fontane, W. (2010). Reference question data mining: A systematic approach to library outreach. Reference \& User Services Quarterly, 49(3), 278-286.

Hines, S. (2009). Librarians at the bounds of rationality: How bounded rationality can help us help others. Behavioral Social Sciences Librarian, 28(3), 80-86. doi: $10.1080 / 01639260903088927$

Joint, N. (2008). Virtual reference, second life and traditional library enquiry services: ANTAEUS. Library Review, 57(6), 417-423. doi: 10.1108/00242530810886689

Nilsen, K. (2006). Comparing users' perspectives of in-person and virtual reference. New Library World, 107(3/4), 91-104. doi: 10.1108/03074800610654871 
Ryan, S. M. (2008). Reference transactions analysis: The cost-effectiveness of staffing a traditional academic reference desk. The Journal of Academic Librarianship, 34 (5), 389-399. doi: 10.1016/j.acalib.2008.06.002

Schachter, D. (2006). The importance of good decision making. Information Outlook, 10(4), $12-13$ 